\title{
Lipids and Cardiovascular Organ Damage in Type 2 Diabetes Mellitus
}

\section{Michaela Kozakova ${ }^{1}$, Carlo Palombo ${ }^{2 *}$}

${ }^{1}$ Department of Clinical and Experimental Medicine, University of Pisa, Pisa, Italy

${ }^{2}$ Department of Surgical, Medical, Molecular Pathology and Critical Care Medicine, University of Pisa, Pisa, Italy

*Corresponding Author: Carlo Palombo, MD, FESC, Department of Surgical, Medical and Molecular Pathology and Critical Care Medicine, University of Pisa, Via Savi 10, 56126 Pisa, Italy, Tel: +39 050 997736; Fax: +39050 997613; E-mail: carlo.palombo@unipi.it

Received: 16 June 2020; Accepted: 30 June 2020; Published: 20 July 2020

Citation: Michaela Kozakova, Carlo Palombo. Lipids and Cardiovascular Organ Damage in Type 2 Diabetes Mellitus. Cardiology and Cardiovascular Medicine 4 (2020): 346-360.

\begin{abstract}
One of the mechanisms underlying increased cardiovascular (CV) risk in patients with type 2 diabetes mellitus is atherogenic dyslipidemia, that is characterized by elevated triglycerides and free fatty acids (FFAs) levels, low levels of high-density lipoprotein cholesterol (HDL) and an excess of small dense low-density lipoprotein particles (sdLDLs). Each component of atherogenic dyslipidemia is associated with $\mathrm{CV}$ events and triggers alterations at different levels of $\mathrm{CV}$ system through different pathways. FFAs and sdLDLs induce endothelial dysfunction, intima-media thickening, plaque formation and arterial stiffening through increase in oxidative stress and inflammation and promoting lipid
\end{abstract}

accumulation and smooth muscle cells (SMCs) proliferation in vascular wall. In contrast, HDL exerts protective effect on arterial wall by increasing nitric oxide availability, by reverse cholesterol transport and by suppression of SMCs proliferation and migration. FFAs overload results in a switch in myocardial substrate utilization, causing changes in myocardial energy metabolism and an increase in baseline oxygen consumption. Accumulation of toxic lipid intermediates in myocardium provokes damage of cellular membrane integrity, organelle dysfunction and apoptosis with consequent decrease in myocardial performance. The structural and functional changes in myocardium can be reversed by therapy with reconstructed HDL. Therefore, the impact of 
atherogenic dyslipidemia on CV system is not limited on accelerated atherosclerosis, but causes different organ damages that must be considered in their complexity.

Keywords: Type 2 diabetes mellitus; Dyslipidemia; Endothelial function; Intima-media thickness; Arterial stiffness; Left ventricular remodeling

\section{Introduction}

The risk of cardiovascular (CV) disease in patients with type 2 diabetes mellitus (T2DM) is increased approximately 2-fold in men and 3-4-fold in women [1]. One of the mechanisms underlying such an increase is diabetic atherogenic dyslipidemia that is characterized by a cluster of interrelated lipids abnormalities, including hypertriglyceridemia, low high-density lipoprotein (HDL) cholesterol and the predominance of small dense low-density lipoproteins (sdLDLs) [2].

Altered metabolism of triglyceride-rich lipoproteins is critical in the development of the diabetic dyslipidemia. Increased flow of free fatty acids (FFAs) and glucose to the liver in the presence of insulin resistance results in increased secretion of large triglycerides-rich very low-density lipoproteins (VLDLs-1) [3-4]. VLDLs-1 secretion depends mainly on substrates availability but may be increased also by other T2DM-related factors, like inflammatory state and low adiponectin concentration. Overproduction of VLDLs-1 particles promotes the generation of sdLDL particles and reduces HDL levels. SdLDLs are more atherogenic than normal-sized LDL particles due to their longer plasma half-life and weaker resistance to oxidative stress [5]. Reduction in HDL levels is a consequence of the exchange of triglycerides and cholesteryl ester between HDL and triglyceride-rich lipoproteins and formation of triglyceride-rich HDL that are quickly cleared from plasma by the action of hepatic lipase [4, 6].

T2DM is a chronic low-grade inflammation state and inflammatory cytokines influence plasma lipid levels. Interleukins (IL) and tumor necrosis factor (TNF) stimulate de novo synthesis of triglyceride-rich lipoproteins in liver and ILs also delay their clearance by decreasing lipoprotein lipase activity [7]. ILs and TNF- $\alpha$ decrease the production of apolipoprotein A-I (apoA-I) and IL-6 enhances its degradation by upregulating the expression and activity of matrixmetalloproteinases (MMPs) [8-10]. In addition, inflammation induces changes in HDL structure that reduce their ability of reverse cholesterol transport as well as their anti-oxidant action [11].

Each component of atherogenic dyslipidemia is associated with $\mathrm{CV}$ events. In meta-analyses of prospective studies, for $1-\mathrm{mmol} / \mathrm{L}$ increase in plasma triglycerides there was a $32 \%$ increase in coronary disease risk for men and $76 \%$ increase in risk for women [12], and for 1-SD increment in HDL concentration, there was a $18 \%$ reduction in the risk of CV events [13], independently of other lipid fractions. In a general population without a history of $\mathrm{CV}$ disease, for $10 \mathrm{mg} / \mathrm{dL}$ increase in sdLDLs there was a $21 \%$ increase in CV disease [14], and in a large prospective cohort of subjects undergoing coronary angiography, an adjusted HR of the fourth FFA quartile for death from CV causes was 1.83 [15]. 
A strong association between atherogenic dyslipidemia and $\mathrm{CV}$ risk reflects the negative impact of lipids on $\mathrm{CV}$ system. Well-known is the role of lipid abnormalities in atherogenesis, yet, FFAs, sdLDLs and decreased or altered HDL may trigger adverse changes at different levels of CV system and thus cause different organ damages. Complex inter-relationships between lipids and inflammation induce endothelial dysfunction, increase in carotid intima-media thickness (CIMT) and plaque formation, arterial stiffening and left ventricular (LV) remodeling and dysfunction (Table 1).

\begin{tabular}{|c|c|c|c|c|}
\hline & $\begin{array}{l}\text { Endothelial } \\
\text { Function }\end{array}$ & IMT and Plaques & Arterial Stiffness & $\begin{array}{l}\text { LV Remodeling and } \\
\text { Dysfunction }\end{array}$ \\
\hline FFAs & $\begin{array}{l}\downarrow \\
\uparrow \text { oxidative stress } \\
\uparrow \text { inflammation } \\
\uparrow \text { apoptosis of ECs \& } \\
\text { EPCs }\end{array}$ & $\begin{array}{l}\text { 个 } \\
\uparrow \text { VSMCs proliferation \& } \\
\text { migration } \\
\uparrow \text { ECM formation } \\
\uparrow \text { inflammation } \\
\uparrow \text { oxidative stress }\end{array}$ & $\begin{array}{l}\uparrow \\
\downarrow \text { NO availability } \\
\uparrow \text { inflammation } \rightarrow \text { MMPs- } \\
\text { activation }\end{array}$ & $\begin{array}{l}\downarrow \text { energetic efficiency } \\
\uparrow \text { oxidative stress } \\
\uparrow \text { apoptosis } \\
\uparrow \text { inflammation }\end{array}$ \\
\hline sdLDLs & $\begin{array}{l}\boldsymbol{v} \\
\uparrow \text { oxidative stress }\end{array}$ & $\begin{array}{l}\text { 个 } \\
\uparrow \text { lipid accumulation } \\
\uparrow \text { inflammation }\end{array}$ & $\begin{array}{l}\text { } \\
\downarrow \text { NO availability } \\
\uparrow \text { inflammation } \rightarrow \text { MMPs- } \\
\text { activation }\end{array}$ & \\
\hline HDL & $\begin{array}{l}\text { 个 } \\
\uparrow \text { eNOS activation } \\
\downarrow \text { inflammation } \\
\downarrow \text { apoptosis } \\
\text { cholesterol efflux } \\
\text { from ECs }\end{array}$ & $\begin{array}{l}\downarrow \\
\text { reverse cholesterol } \\
\text { transport } \\
\downarrow \text { VSMCs proliferation \& } \\
\text { migration }\end{array}$ & $\begin{array}{l}\downarrow \\
\uparrow \text { eNOS activation } \\
\downarrow \text { inflammation } \\
\text { positive impact on VSMCs } \\
\text { phenotype } \\
\& \text { ECM expression }\end{array}$ & $\begin{array}{l}\downarrow \text { inflammation } \\
\downarrow \text { oxidative stress }\end{array}$ \\
\hline
\end{tabular}

Table 1: Lipids and Cardiovascular Biomarker

Legend: EPCs: endothelial progenitor cells; ECs: endothelial cells; eNOS: endothelial nitric oxide synthase; NO: nitric oxide; VSMCs: vascular smooth muscle cells; ECM: extracellular matrix; LV: left ventricular; MMPs: mMatrix-metalloproteinases 
All these alterations are established biomarkers of $\mathrm{CV}$ risk as numerous prospective studies have demonstrated their independent association with $\mathrm{CV}$ events. A $1 \%$ increase in brachial flow-mediates dilation decreases the risk of CV events by $13 \%$ [16], 1-SD increase in CIMT increases the risk of myocardial infarction and stroke by $26 \%$ and $32 \%$, respectively [17], 1-SD increase in carotid-femoral pulse-wave velocity increases the risk of $\mathrm{CV}$ events by $47 \%$ [18], the presence of LV hypertrophy increases the risk of major CV events by $53 \%$ [19], and a $10 \%$ decrease in $\mathrm{LV}$ ejection fraction below $45 \%$ increases the risk of all-cause mortality by $39 \%$ [20].

\section{Endothelial Dysfunction}

Endothelium is the major regulator of vascular homeostasis, since it maintains the balance between vasodilation and vasoconstriction, inhibition and stimulation SMCs proliferation and migration, thrombogenesis and fibrinolysis. Accordingly, endothelial dysfunction is characterized by a shift of endothelial actions towards reduced vasodilation, a proinflammatory and prothrombic state. Mechanisms that participate on endothelial dysfunction include diminished production and/or availability of nitric oxide (NO), oxidative stress, endoplasmic reticulum stress, metabolic stress and inflammation [21].

Lipoprotein lipase located on the endothelial surface or within the arterial intima hydrolyzes triglycerides into FFAs and monoacylglycerols [22]. FFAs activate transcription factors that trigger oxidative stress and inflammation in the endothelium, facilitate apoptosis of endothelial cells and endothelial progenitor cells [23-25]. FFAs increase oxidative stress by generating reactive oxygen species (ROS) through protein kinase
C-dependent activation of NADPH oxidase [26], by increased production of superoxide $\left(\mathrm{O}_{2}^{-}\right)$in mitochondrial respiratory chain [27] and by decreased NO production due to attenuation of endothelial $\mathrm{Ca}^{2+}$ signaling [28]. FFAs induce inflammation by activation of TNF- $\alpha$, IL1- $\beta$, and IL-6 through the nuclear factor- $\kappa \mathrm{B}(\mathrm{NF}-\kappa \mathrm{B})$ pathway [29].

Experimental studies demonstrated that a short-term exposure of endothelial cells to FFAs inhibits endothelial nitric oxide synthase (eNOS) activity and increases $\mathrm{O}_{2}{ }^{-}$release [24], while a long-term exposure triggers apoptosis and reduces total eNOS levels [25]. Clinical studies in healthy volunteers confirm the impact of FFA on endothelial function. The interventions leading to acute increase of plasma FFA, like ingestion of a single high-fat meal or intralipid infusion, impair endothelium-dependent vasodilation, but do not affect the flow response to nitroprusside [30-31].

SdLDLs decrease production of cytoprotective NO and increase production of cytotoxic peroxynitrite $\left(\mathrm{ONOO}^{-}\right)$in endothelial cells [32]. In healthy men, LDL size has been shown to correlate with endothelium dependent vasodilation; men with small LDL particles had a $39 \%$ lower blood flow response to acetylcholine than men with large LDL particles, independently of LDL cholesterol concentrations [33]. In T2DM patients, LDL size predicted the forearm blood flow response to acetylcholine, independently of age, gender and blood pressure [34].

HDL exerts protective effect on endothelium by activating endothelial nitric oxide synthase (eNOS) and by reducing inflammation, apoptosis and 
thrombosis. HDL particles, above all apoA-I, activate protein kinase Akt and eNOS through interactions with receptors present on endothelial cells (scavenger receptor class $\mathrm{B}$, type 1 and sphingosine-1-phosphate receptor) [35-36]. HDL also inhibits TNF- $\alpha$-dependent NF- $\kappa B$ activation [37] and mediates cholesterol efflux from endothelial cells that decreases the cholesterol content of caveolae, reduces inhibitory interaction of eNOS with caveolin-1 and promotes NO synthesis [38]. The positive impact of HDL on endothelial function was demonstrated in hypercholesterolemic men with reduced endothelium-dependent response of forearm blood flow to acetylcholine and preserved endothelium-independent response to sodium nitroprusside. An intravenous infusion of reconstructed HDL increased plasma HDL levels and enhanced the acetylcholine-induced increase in forearm blood flow without affecting the response to sodium nitroprusside [39].

\section{Carotid Intima-Media Thickening and Plaques}

Increase in carotid intima-media thickness (CIMT), which represents a combined measure of intimal and medial thicknesses, is considered a very early marker of subclinical atherosclerosis or adverse arterial remodeling, while the presence of carotid plaques reflects more advanced atherosclerotic lesion.

FFAs may alter CIMT by several mechanisms. At the medial layer, FFAs stimulate vascular SMCs proliferation and migration and modify the expression of genes controlling extracellular matrix formation. At the intimal level, FFAs induce oxidative stress, apoptosis, and an inflammatory response. An independent association between circulating FFAs and CIMT was demonstrated in healthy men [40] as well as in renal transplant recipients [41]. In T2DM patients, FFA-rich areas were found within carotid plaques, and the pattern of distribution of plaque FFAs was similar to that of monocyte chemoattractant protein-1 and activated NF- $\mathrm{KB}$, i.e. to that of inflammation [42].

Lipid accumulation in the arterial wall is a crucial event in the development of atherosclerotic lesions. While the native LDLs does not trigger lipid accumulation, modified particles, like oxidized and glycated LDLs, are highly atherogenic and possess proinflammatory properties. SdLDLs have a higher susceptibility to lipid peroxidative modification, when compared to larger LDLs, which can be explained by their composition (lower lipid and higher apoB content) [43] and by lower concentration of antioxidants [44]. SdLDLs are also more susceptible to glycation since apoB is preferentially glycated in sdLDL particles [45]. Higher glycation and oxidation of sdLDLs are accountable for increased atherogenic potential. In healthy men, plasma sdLDLs were directly and independently associated with CIMT [46], in patients with T2DM and prediabetes, the proportion of sdLDL particles at baseline predicted CIMT increase at 2 years [47], and in patients with acute cerebral infarction, sdLDLs were an independent risk factor for unstable carotid plaques [48].

The most important mechanism by which HDL prevents the initiation and progression of atherosclerotic changes is a reverse cholesterol transport. HDL scavenges cholesterol from the peripheral vasculature and transports it to the liver, where it is excreted in the biliary system. Cholesterol is removed from the monocyte macrophage system by 
passive diffusion, by facilitated diffusion mediated by scavenger receptor class $\mathrm{B}$, type 1 , or by active pathways mediated by the ATP binding cassette transporters [49].

Experimental studies in animals have demonstrated a reduction in plaque size, lipid, and macrophage content with infusions of either human HDL or reconstituted HDL containing apoA-I [50]. In humans, intravenous infusions of reconstructed HDL containing wild-type apoA-I did not reduce the volume of coronary plaques but had favorable effect on a plaque echogenicity index consistent with potential plaque stabilization [51]. This is in agreement with studies on carotid arteries, showing that low HDL levels are associated with echolucent, rupture-prone plaques [52]. Different studies also demonstrated an inverse association between HDL and CIMT [53], however, these associations probably reflect HDLinduced suppression of SMCs proliferation and migration rather than a reverse cholesterol transport [54].

\section{Arterial Stiffness}

Arterial stiffness depends mainly on the relative content of 2 structural proteins, elastin and collagen. Disarrangement and fragmentation of elastin fibers together with overproduction and cross-linking of collagen lead to arterial stiffening. In T2DM patients, arterial stiffness is increased across all age groups and one of the main mechanisms involved is the formation of advanced glycation end-products (AGEs), causing cross-linking of collagen molecules. On arterial stiffening in diabetes may participate also hyperinsulinemia- and hyperglycemia-induced increase in the local activity of the renin-angiotensin- aldosterone system that promotes arterial wall hypertrophy and fibrosis.

The role of lipids in arterial stiffening is mediated by endothelial dysfunction and inflammation. NO, whose reduced bioavailability represents the molecular basis of endothelial dysfunction, is involved also in the regulation of arterial distensibility, and NO donors have been shown to reduce augmentation index and wave reflection, independently of their effect on blood pressure. Systemic and local inflammation trigger arterial stiffening through cytokines that induce transcription and activation of MMPs. MMPs cleave the protein components of the extracellular matrix, including elastin, and thereby play a central role in vascular remodeling and stiffening. Numerous crosssectional and prospective clinical studies demonstrated the independent association of arterial stiffness indices with triglycerides, FFAs and sdLDL (55-57) as well as with cytokines and MMPs, not only in T2DM patients but also in general population, healthy subjects, patients with hypertension or chronic inflammatory disease [54, 58-59].

In contrast to FFAs and sdLDL, HDL can prevent arterial stiffening. ATP binding cassette transporter A1 (ABCA-1), one of the cell membrane proteins participating in the cholesterol efflux from cells to apolipoproteins, has been shown to modulate vascular SMCs phenotypic switch and to suppress the expression of inflammatory cytokines that may activate MMPs [60-61]. In addition, apolipoprotein E (apoE) and apoE-containing HDL suppress extracellular matrix gene expression in response to mechanical stimuli [62] and upregulate ABCA-1 expression [63]. Indeed, in healthy subjects, aortic 
stiffness was inversely related to ABCA-1-dependent serum cholesterol efflux capacity [64], and ApoEdeficient mice showed increased aortic stiffness and focal fragmentation of elastic fibers in aortic wall [65].

\section{Remodeling and Dysfunction (Diabetic Cardiomyopathy)}

The heart is the organ with the highest oxygen consumption rate per weight unit. For adenosine triphosphate (ATP) production, the heart can utilize different substrates in order to maintain consistent ATP production with changing substrate availability. In normal adult heart, $\sim 60-90 \%$ of the acetyl-CoA comes from $\beta$-oxidation of fatty acids, and 10-40\% from the oxidation of pyruvate that is derived in approximately equal amounts from glycolysis and lactate oxidation. In diabetic heart, there is a shift towards FFAs utilization. This could be explained by the fact that the rate of FFAs uptake by myocardium is not hormonally regulated but largely driven by FFAs plasma concentration, while glucose uptake is regulated by insulin. Combination of insulin resistance and FFA overload favors FFA utilization. In addition, increased FFAs flow stimulates cardiac peroxisome proliferator-activated receptor- $\alpha$ (PPAR- $\alpha$ ) that upregulates the lipid metabolic pathway while the products of mitochondrial FFA oxidation repress cellular glucose utilization through allosteric inhibition of glycolytic enzymes [66]. As a result of all these changes, diabetic myocardium depends almost entirely on FFAs as the energy source [67]. Substrate switch from glucose to FFAs reduces the efficiency of oxidative phosphorylation since every molecule of ATP generated from the oxidation of FFA costs 0.3 molecules of oxygen more than ATP generated from glucose [68]. Indeed, experimental studies in animals demonstrated that diabetic hearts consume $\geq 30 \%$ more oxygen than non-diabetic hearts, while generating the same contractile force [69].

Seventy-ninety percent of FFAs taken up by the myocardium is rapidly utilized for energy metabolism in the mitochondria while $10-30 \%$ is stored as triacylglycerol to be rapidly mobilized in conditions of increased myocardial energy demands. When the capacity for mitochondrial fatty acid $\beta$-oxidation cannot keep up with the excessive FFAs delivery, a number of various toxic lipid intermediates, particularly diacylglycerols and ceramides, begins to accumulate in myocardium inducing oxidative stress that results in damage of cellular membrane integrity, organelle dysfunction and apoptosis [70]. In animal models, obese Zucker diabetic rats showed elevated intramyocardial accumulation of triglycerides and ceramide, increased apoptosis and LV dilatation with reduced contractility. Suppression of plasma triglyceride with the PPAR $\gamma$ agonist troglitazone lowers myocardial triglyceride and ceramide content, prevent apoptosis and deterioration of cardiac function [71].

Corresponding findings were observed in human heart using proton magnetic resonance spectroscopy. In a study comparing lean normoglycemic subjects, subjects with impaired glucose tolerance and diabetic subjects, myocardial triglyceride content was 2.3-fold and 2.1-fold higher in subjects with impaired glucose tolerance and $\mathrm{T} 2 \mathrm{DM}$, respectively, as compared to lean normoglycemic subjects. LV systolic function was preserved in all 3 groups, yet, the estimate of diastolic function was abnormal in impaired glucose tolerance and T2DM groups [72]. Acute 
pharmacologic inhibition of adipose tissue lipolysis by a nicotinic acid analogue in diabetic patients resulted in reduction of FFAs plasma levels and myocardial lipids content by $69 \%$ and $39 \%$, respectively, and in increase of ejection fraction by $15 \%$. Changes in plasma FFAs concentration strongly correlated with changes in myocardial lipid content and with ejection fraction $(\mathrm{r}=0.71$ and 0.65$)$ [73].

Besides altered energy metabolism and intramyocardial lipid accumulation, diabetic cardiomyopathy is characterized by myocardial inflammation and fibrosis. Several molecular mechanisms may be involved in diabetes-related myocardial inflammation, yet majority of these mechanisms converge towards the activation of the NF- $\kappa B$ pathway, with consequent upregulation of cytokines, chemokines and adhesion molecules, that can be attenuated by PPAR- $\beta / \delta$ [74]. TNF- $\alpha$, IL- 6 and IL-1 $\beta$ directly promote cardiomyocyte growth and hypertrophy as well as contractile dysfunction [75-76]. TNF- $\alpha$ and IL-6 also stimulate cardiac fibroblast proliferation and collagen production, whereas IL-1 $\beta$ activates MMPs [77-78], all of which generate myocardial fibrosis.

HDL and apoA-I have important anti-inflammatory potential. They can remove active TNF- $\alpha$, inhibit the production of IL- $1 \beta$ and TNF- $\alpha$, induce the expression of anti-inflammatory cytokine IL-10 and reduce expression of VCAM-1, ICAM-1 and E-selectin [79]. Several experimental studies investigated the antiinflammatory impact of HDL on diabetic heart. In streptozotocin-induced rat model of diabetes, apoA-I gen transfer increased HDL levels, decreased cell adhesion molecules and TNF- $\alpha$ expression and decreased total collagen content in myocardium [80]. Mice fed with a high-sugar/high-fat diet developed cardiac hypertrophy with increased interstitial and perivascular fibrosis and impaired systo-diastolic function. Treatment with reconstituted $\mathrm{HDL}_{\text {Milano }}$ reversed pathological remodelling and cardiac dysfunction [81].

In clinical studies, LV mass and relative wall thickness were inversely related to HDL in general population and in hypertensive subjects [82-83]. LV systolic function, assessed as ejection fraction or as a velocity of LV longitudinal shortening, and LV diastolic function, assessed as the longitudinal velocity of early diastolic filling, correlated with HDL, both in diabetic patients and non-diabetic subjects [53, 84-86].

\section{Conclusions}

The prevalence of diabetic dyslipidemia is high and each of its components is able to provoke deleterious changes at different levels of CV system (Table 1). Common perception of $\mathrm{CV}$ risk in T2DM patients is associated above all with accelerated atherosclerotic process, yet diabetes-related metabolic abnormalities, and lipid abnormalities in particular, had much wider negative effect on CV system as we try to summarize in this paper. It must be considered that the adverse impact of diabetic dyslipidemia on different parts of the CV system should be evaluated in its complexity. Diabetic patients, whose heart has impaired systolediastolic performance and consummate 30\% more oxygen at resting conditions, and whose afterload and therefore workload is increased due to arterial stiffening, can be expected to develop myocardial ischemia or heart failure with a lower degree of coronary stenosis or at a lower hemodynamic load than 
non-diabetic subjects. Therefore, it is of utmost importance to understand the complex mechanism through which lipids may alter CV structure and function so that their negative impact can be detected in preclinical phase by non-invasive imaging techniques (ultrasound, magnetic resonance imaging, positron emission tomography) and mitigated by appropriate life-style and pharmacologic interventions [87].

\section{Conflict of Interest}

No conflict of interest to be declared.

\section{References}

1. Fox CS, Golden SH, Anderson C, et al. American Heart Association Diabetes Committee of the Council on Lifestyle and Cardiometabolic Health; Council on Clinical Cardiology, Council on Cardiovascular and Stroke Nursing, Council on Cardiovascular Surgery and Anesthesia, Council on Quality of Care and Outcomes Research; American Diabetes Association. Update on prevention of cardiovascular disease in adults with type 2 diabetes mellitus in light of recent evidence: a scientific statement from the American Heart Association and the American .... Diabetes Care 38 (2015): 1777-1803.

2. Taskinen MR, Borén J. New insights into the pathophysiology of dyslipidemia in type 2 diabetes. Atherosclerosis 239 (2015): 483495.

3. Sugden M, Holness M. Pathophysiology of diabetic dyslipidemia: implications for atherogenesis and treatment. Clinical Lipidology 6 (2011): 401-411.
4. Adiels M, Olofsson SO, Taskinen MR, et al. Overproduction of very low-density lipoproteins is the hallmark of the dyslipidemia in the metabolic syndrome. Arteriosclerosis, Thrombosis, and Vascular Biology 28 (2008): 1225-1236.

5. Packard CJ, Demant T, Stewart JP, et al. Apolipoprotein B metabolism and the distribution of VLDL and LDL subfractions. Journal of Lipid Research 41 (2000): 305317.

6. Ji J, Watts GF, Johnson AG, et al. Highdensity lipoprotein (HDL) transport in the metabolic syndrome: application of a new model for HDL particle kinetics. The Journal of Clinical Endocrinology \& Metabolism 91 (2006): 973-979.

7. Nonogaki KA, Fuller GM, Fuentes NL, et al. Interleukin-6 stimulates hepatic triglyceride secretion in rats. Endocrinology 136 (1995): 2143-2149.

8. Ettinger WH, Varma VK, Sorci-Thomas M, et al. Cytokines decrease apolipoprotein accumulation in medium from Hep G2 cells. Arteriosclerosis and Thrombosis: A Journal of Vascular Biology 14 (1994): 8-13.

9. Kossakowska AE, Edwards DR, Prusinkiewicz C, et al. Interleukin-6 regulation of matrix metalloproteinase (MMP-2 and MMP-9) and tissue inhibitor of metalloproteinase (TIMP-1) expression in malignant non-Hodgkin's lymphomas. Blood, The Journal of the American Society of Hematology 94 (1999): 2080-2089.

10. Lindstedt L, Saarinen J, Kalkkinen N, et al. Matrix metalloproteinases-3, -7 , and -12 , but not -9 , reduce high density lipoprotein- 
induced cholesterol efflux from human macrophage foam cells by truncation of the carboxyl terminus of apolipoprotein A-I. Parallel losses of pre-beta particles and the high affinity component of efflux. J Biol Chem 274 (1999): 22627-22634.

11. Feingold KR, Grunfeld C. Effect of inflammation on HDL structure and function. Current Opinion in Lipidology 27 (2016): 521-530.

12. Hokanson JE, Austin MA. Plasma triglyceride level is a risk factor for cardiovascular disease independent of highdensity lipoprotein cholesterol level: a metaanalysis of population-based prospective studies. Journal of Cardiovascular Risk 3 (1996): 213-219.

13. Wu Y, Fan Z, Tian Y, et al. Relation between high density lipoprotein particles concentration and cardiovascular events: a meta-analysis. Lipids in Health and Disease 17 (2018): 142.

14. Arai H, Kokubo Y, Watanabe M, et al. Small dense low-density lipoproteins cholesterol can predict incident cardiovascular disease in an urban Japanese cohort: the Suita study. Journal of Atherosclerosis and Thrombosis 20 (2013): 195-203.

15. Pilz S, Scharnagl H, Tiran B, et al. Free fatty acids are independently associated with allcause and cardiovascular mortality in subjects with coronary artery disease. The Journal of Clinical Endocrinology \& Metabolism 91 (2006): 2542-2547.

16. Inaba Y, Chen JA, Bergmann SR. Prediction of future cardiovascular outcomes by flowmediated vasodilatation of brachial artery: a meta-analysis. The International Journal of Cardiovascular Imaging 26 (2010): 631-640.

17. Lorenz MW, Sitzer M, Markus HS, et al. Prediction of clinical cardiovascular events with carotid intima-media thickness: A systematic review and meta-analysisResponse. Circulation 116 (2007): 318.

18. Vlachopoulos C, Aznaouridis K, Stefanadis C. Prediction of cardiovascular events and all-cause mortality with arterial stiffness: a systematic review and meta-analysis. Journal of the American College of Cardiology 55 (2010): 1318-1327.

19. Zhang H, Hu L, Wei X. Prognostic value of left ventricular hypertrophy in hypertensive patients: A meta-analysis of electrocardiographic studies. The Journal of Clinical Hypertension 22 (2020): 254-260.

20. Solomon SD, Anavekar N, Skali H, et al. Influence of ejection fraction on cardiovascular outcomes in a broad spectrum of heart failure patients. Circulation 112 (2005): 3738-3744.

21. Pober JS, Min W, Bradley JR. Mechanisms of endothelial dysfunction, injury, and death. Annual Review of Pathology: Mechanisms of Disease 4 (2009): 71-95.

22. Kajikawa M, Higashi Y. Triglycerides and endothelial function: Molecular biology to clinical perspective. Current Opinion in Lipidology 30 (2019): 364-369.

23. Toborek M, Lee YW, Garrido R, et al. Unsaturated fatty acids selectively induce an inflammatory environment in human endothelial cells. The American Journal of Clinical Nutrition 75 (2002): 119-125. 
24. Kim F, Tysseling KA, Rice J, et al. Free fatty acid impairment of nitric oxide production in endothelial cells is mediated by IKK $\beta$. Arteriosclerosis, Thrombosis, and Vascular Biology 25 (2005): 989-994.

25. Artwohl M, Roden M, Waldhäusl W, et al. Free fatty acids trigger apoptosis and inhibit cell cycle progression in human vascular endothelial cells. The FASEB journal 18 (2004): 146-148.

26. Inoguchi $\mathrm{T}$, Li $\mathrm{P}$, Umeda $\mathrm{F}$, et al. High glucose level and free fatty acid stimulate reactive oxygen species production through protein kinase C--dependent activation of NAD (P) H oxidase in cultured vascular cells. Diabetes 49 (2000): 1939-1945.

27. Di Paola M, Lorusso M. Interaction of free fatty acids with mitochondria: coupling, uncoupling and permeability transition. Biochimica et Biophysica Acta (BBA)Bioenergetics 1757 (2006): 1330-1337.

28. Esenabhalu VE, Schaeffer G, Graier WF. Free fatty acid overload attenuates $\mathrm{Ca} 2+$ signaling and NO production in endothelial cells. Antioxidants and Redox Signaling 5 (2003): 147-153.

29. Li H, Li H, Bao Y, et al. Free fatty acids induce endothelial dysfunction and activate protein kinase $\mathrm{C}$ and nuclear factor- $\mathrm{\kappa B}$ pathway in rat aorta. International Journal of Cardiology 152 (2011): 218-224.

30. Vogel RA, Corretti MC, Plotnick GD. Effect of a single high-fat meal on endothelial function in healthy subjects. The American Journal of Cardiology 79 (1997): 350-354.

31. Steinberg HO, Tarshoby M, Monestel R, et al. Elevated circulating free fatty acid levels impair endothelium-dependent vasodilation. The Journal of Clinical Investigation 100 (1997): 1230-1239.

32. Hua J, Malinski T. Variable Effects Of LDL Subclasses Of Cholesterol On Endothelial Nitric Oxide/Peroxynitrite Balance-The Risks And Clinical Implications For Cardiovascular Disease. International Journal of Nanomedicine 14 (2019): 8973.

33. Vakkilainen J, Mäkimattila S, SeppäläLindroos A, et al. Endothelial dysfunction in men with small LDL particles. Circulation 102 (2000): 716-721.

34. Woodman RJ, Watts GF, Playford DA, et al. Oxidized LDL and small LDL particle size are independently predictive of a selective defect in microcirculatory endothelial function in type 2 diabetes. Diabetes, Obesity and Metabolism 7 (2005): 612-617.

35. Yuhanna IS, Zhu Y, Cox BE, et al. Highdensity lipoprotein binding to scavenger receptor-BI activates endothelial nitric oxide synthase. Nature Medicine 7 (2001): 853-857.

36. Nofer JR, Van Der Giet M, Tölle M, et al. HDL induces NO-dependent vasorelaxation via the lysophospholipid receptor S1P 3. The Journal of Clinical Investigation 113 (2004): 569-581.

37. Norata GD, Catapano AL. Molecular mechanisms responsible for the antiinflammatory and protective effect of HDL on the endothelium. Vascular Health and Risk Management 1 (2005): 119.

38. Terasaka N, Westerterp M, Koetsveld J, et al. ATP-binding cassette transporter G1 and high-density lipoprotein promote endothelial NO synthesis through a decrease in the 
interaction of caveolin-1 and endothelial NO synthase. Arteriosclerosis, Thrombosis, and Vascular Biology 30 (2010): 2219-2225.

39. Spieker LE, Sudano I, Hürlimann D, et al. High-density lipoprotein restores endothelial function in hypercholesterolemic men. Circulation 105 (2002): 1399-1402.

40. Kozakova M, Natali A, Dekker J, et al. Insulin sensitivity and carotid intima-media thickness: relationship between insulin sensitivity and cardiovascular risk study. Arteriosclerosis, Thrombosis, and Vascular Biology 33 (2013): 1409-1417.

41. Armstrong KA, Hiremagalur B, Haluska BA, et al. Free fatty acids are associated with obesity, insulin resistance, and atherosclerosis in renal transplant recipients. Transplantation 80 (2005): 937-944.

42. Mas S, Martínez-Pinna R, Martín-Ventura JL, et al. Local non-esterified fatty acids correlate with inflammation in atheroma plaques of patients with type 2 diabetes. Diabetes 59 (2010): 1292-1301.

43. Ohmura H, Mokuno H, Sawano M, et al. Lipid compositional differences of small, dense low-density lipoprotein particle influence its oxidative susceptibility: possible implication of increased risk of coronary artery disease in subjects with phenotype B. Metabolism-Clinical and Experimental 51 (2002): 1081-1087.

44. Tribble DL, Rizzo M, Chait A, et al. Enhanced oxidative susceptibility and reduced antioxidant content of metabolic precursors of small, dense low-density lipoproteins. The American Journal of Medicine 110 (2001): 103-110.
45. Soran H, Durrington PN. Susceptibility of LDL and its subfractions to glycation. Current Opinion in Lipidology 22 (2011): 254-261.

46. Shen $\mathrm{H}, \mathrm{Xu} \mathrm{L}, \mathrm{Lu} \mathrm{J}$, et al. Correlation between small dense low-density lipoprotein cholesterol and carotid artery intima-media thickness in a healthy Chinese population. Lipids in Health and Disease 14 (2015): 137.

47. Gerber PA, Thalhammer C, Schmied C, et al. Small, dense LDL particles predict changes in intima media thickness and insulin resistance in men with type 2 diabetes and prediabetes-a prospective cohort study. PloS one 8 (2013): e72763.

48. QiaoZhen X, AiGuo M, Tong W, et al. Correlation between of small dense lowdensity lipoprotein cholesterol with acute cerebral infarction and carotid atherosclerotic plaque stability. Journal of Clinical Laboratory Analysis 33 (2019): e22891.

49. Phillips MC. Molecular mechanisms of cellular cholesterol efflux. Journal of Biological Chemistry 289 (2014): 2402024029.

50. Di Bartolo BA, Psaltis PJ, Bursill CA, et al. Translating evidence of HDL and plaque regression. Arteriosclerosis, Thrombosis, and Vascular Biology 38 (2018): 1961-1968.

51. Tardif JC, Grégoire J, L'Allier PL, et al. Effects of reconstituted high-density lipoprotein infusions on coronary atherosclerosis: a randomized controlled trial. Jama 297 (2007): 1675-1682.

52. Mathiesen EB, Bønaa KH, Joakimsen O. Low levels of high-density lipoprotein cholesterol are associated with echolucent carotid artery 
plaques: the Troms $\varnothing$ study. Stroke 32 (2001): 1960-1965.

53. Kozakova M, Morizzo C, Goncalves I, et al. Cardiovascular organ damage in type 2 diabetes mellitus: the role of lipids and inflammation. Cardiovascular Diabetology 18 (2019): 1-1.

54. Tamama K, Tomura H, Sato K, et al. Highdensity lipoprotein inhibits migration of vascular smooth muscle cells through its sphingosine 1-phosphate component. Atherosclerosis 178 (2005): 19-23.

55. Wang X, Ye P, Cao R, et al. Triglycerides are a predictive factor for arterial stiffness: a community-based 4.8-year prospective study. Lipids in Health and Disease 15 (2016): 97.

56. Tabara Y, Takahashi Y, Setoh K, et al. Synergistic association of elevated serum free fatty acid and glucose levels with large arterial stiffness in a general population: The Nagahama Study. Metabolism 65 (2016): 6672.

57. Li G, Wu HK, Wu XW, et al. Small dense low density lipoprotein-cholesterol and cholesterol ratios to predict arterial stiffness progression in normotensive subjects over a 5-year period. Lipids in Health and Disease 17 (2018): 27.

58. Tuttolomondo A, Pecoraro R, Buttà C, et al. Arterial stiffness indexes and serum cytokine levels in seronegative spondyloarthritis: relationships between stiffness markers and metabolic and immunoinflammatory variables. Scandinavian Journal of Rheumatology 44 (2015): 474-479.

59. Yasmin, Wallace S, McEniery CM, et al. Matrix metalloproteinase-9 (MMP-9), MMP-
2, and serum elastase activity are associated with systolic hypertension and arterial stiffness. Arteriosclerosis, Thrombosis, and Vascular Biology 25 (2005): 372-378.

60. Liao S, McLachlan CS. Cholesterol Efflux: Does It Contribute to Aortic Stiffening?. Journal of Cardiovascular Development and Disease 5 (2018): 23.

61. Tang C, Liu Y, Kessler PS, et al. The macrophage cholesterol exporter ABCA1 functions as an anti-inflammatory receptor. Journal of Biological Chemistry 284 (2009): 32336-32343.

62. Kothapalli D, Liu SL, Bae YH, et al. Cardiovascular protection by ApoE and ApoE-HDL linked to suppression of ECM gene expression and arterial stiffening. Cell Reports 2 (2012): 1259-1271.

63. Zhao Y, Chen X, Yang $\mathrm{H}$, et al. A novel function of apolipoprotein E: upregulation of ATP-binding cassette transporter A1 expression. PLoS One 6 (2011): e21453.

64. Favari E, Ronda N, Adorni MP, et al. ABCA1-dependent serum cholesterol efflux capacity inversely correlates with pulse wave velocity in healthy subjects. Journal of Lipid Research 54 (2013): 238-243.

65. Wang YX, Halks-Miller M, Vergona R, et al. Increased aortic stiffness assessed by pulse wave velocity in apolipoprotein E-deficient mice. American Journal of Physiology-Heart and Circulatory Physiology 278 (2000): H428-H434.

66. Jia G, Hill MA, Sowers JR. Diabetic cardiomyopathy: an update of mechanisms contributing to this clinical entity. Circulation Research 122 (2018): 624-638. 
67. Stanley WC, Recchia FA, Lopaschuk GD. Myocardial substrate metabolism in the normal and failing heart. Physiological Reviews 85 (2005): 1093-1129.

68. Hinkle PC. P/O ratios of mitochondrial oxidative phosphorylation. Biochimica et Biophysica Acta (BBA)-Bioenergetics 1706 (2005): 1-1.

69. Mazumder PK, O’Neill BT, Roberts MW, et al. Impaired cardiac efficiency and increased fatty acid oxidation in insulin-resistant ob/ob mouse hearts. Diabetes 53 (2004): 23662374.

70. Zlobine I, Gopal K, Ussher JR. Lipotoxicity in obesity and diabetes-related cardiac dysfunction. Biochimica et Biophysica Acta (BBA)-Molecular and Cell Biology of Lipids 1861 (2016): 1555-1568.

71. Zhou YT, Grayburn P, Karim A, et al. Lipotoxic heart disease in obese rats: implications for human obesity. Proceedings of the National Academy of Sciences 97 (2000): 1784-1789.

72. McGavock JM, Lingvay I, Zib I, et al. Cardiac steatosis in diabetes mellitus: a ${ }^{1} \mathrm{H}-$ magnetic resonance spectroscopy study. Circulation 116(2007): 1170-1175.

73. Wolf $\mathrm{P}$, Winhofer $\mathrm{Y}$, Krssak $\mathrm{M}$, et al. Suppression of plasma free fatty acids reduces myocardial lipid content and systolic function in type 2 diabetes. Nutr Metab Cardiovasc Dis 26 (2016): 387-392.

74. Alvarez-Guardia D, Palomer X, Coll T, et al. $\mathrm{PPAR} \beta / \delta$ activation blocks lipid-induced inflammatory pathways in mouse heart and human cardiac cells. Biochim Biophys Acta 1811 (2011): 59-67.
75. Yokoyama T, Nakano M, Bednarczyk JL, et al. Tumor necrosis factor-alpha provokes a hypertrophic growth response in adult cardiac myocytes. Circulation 95 (1997): 1247-1252.

76. Finkel MS, Oddis CV, Jacob TD, et al. Negative inotropic effects of cytokines on the heart mediated by nitric oxide. Science 257 (1992): 387-389.

77. Venkatachalam K, Venkatesan B, Valente AJ, et al. WISP1, a pro-mitogenic, pro-survival factor, mediates tumor necrosis factor-alpha (TNF-alpha)-stimulated cardiac fibroblast proliferation but inhibits TNF-alpha-induced cardiomyocyte death. J Biol Chem 284 (2009): 14414-14427.

78. Zhang Y, Wang JH, Zhang YY, et al. Deletion of interleukin-6 alleviated interstitial fibrosis in streptozotocin-induced diabetic cardiomyopathy of mice through affecting TGF $\beta 1$ and miR-29 pathways. Sci Rep 6 (2016): 23010.

79. Spillmann F, Van Linthout S, Tschöpe C. Cardiac effects of HDL and its components on diabetic cardiomyopathy. Endocr Metab Immune Disord Drug Targets 12 (2012): 132147

80. Van Linthout S, Spillmann F, Riad A, et al. Human apolipoprotein A-I gene transfer reduces the development of experimental diabetic cardiomyopathy. Circulation 117 (2008): 1563-1573.

81. Mishra M, Muthuramu I, Aboumsallem JP, et al. Reconstituted HDL (Milano) treatment efficaciously reverses heart failure with preserved ejection fraction in mice. Int $\mathbf{J}$ Mol Sci 19 (2018): 3399. 
82. Ferrara AL, Vaccaro O, Cardoni O, et al. Is there a relationship between left ventricular mass and plasma glucose and lipids independent of body mass index? Results of the Gubbio Study. Nutr Metab Cardiovasc Dis. 13 (2003): 126-132.

83. Schillaci G, Vaudo G, Reboldi G, et al. Highdensity lipoprotein cholesterol and left ventricular hypertrophy in essential hypertension. J Hypertens 19 (2001;19): 2265-2270.

84. Kim E-H, Seo H-A. HDL level is associated with left ventricular ejection fraction in type 2 diabetic patients (Abstract). BES 2017, Harrogate, UK, Endocrine Abstracts 50 PL1

85. Horio T, Miyazato J, Kamide $\mathrm{K}$, et al. Influence of low high-density lipoprotein cholesterol on left ventricular hypertrophy and diastolic function in essential hypertension. Am J Hypertens 16 (2003): 938-944.

86. Rueda-Ochoa OL, Smiderle-Gelain MA, Rizopoulos D, et al. Risk factors for longitudinal changes in left ventricular diastolic function among women and men. Heart 105 (2019): 1414-1422.

87. Mach F, Baigent C, Catapano AL, et al; ESC Scientific Document Group. 2019 ESC/EAS Guidelines for the management of dyslipidaemias: lipid modification to reduce cardiovascular risk. Eur Heart J 41 (2020): 111-188. 